\title{
sensors
}

ISSN 1424-8220

(C) 2005 by MDPI

http://www.mdpi.net/sensors

\section{Preface for Publication of the Special Issue of I3S 2004}

Analytical chemistry is an indispensable cross discipline and has been developed into analytical sciences. Sensors are important tools of analytical chemistry and a core of electronics, physics, chemistry and biology, which are playing key roles in detection, separation, and characterization in industrial, environmental, biological and medical sciences. It is our great pleasure to publish this special issue with the papers selected from the Second International Symposium on Sensor Science (I3S 2004) held from 29 May to 3 June, 2004 in Nanjing University, Nanjing, China.

This symposium focused on the topics in electrochemical sensors, optical sensors, biosensors and bioanalytical sensors in medicine, $\mathrm{pH}$ sensors, gas sensors, carbon nanotubes sensors, nanosensors and nano technology, electrical sensors, laser sensors, corrosion sensors, ceramic sensors, sensors for environmental monitoring and sensors analysis software. 131 eminent professors, scientists and researchers actively participated in this symposium from Mainland, Hong Kong and Taiwan in China and other 18 countries. Nine plenary lectures and 46 invited lectures were presented on this symposium. We received 33 full papers out of the 131 abstracts presented on I3S 2004. After peer review 14 articles in related areas have been accepted for publication in this special issue. These papers enlightened the recent progress in sensors technology.

This issue of the Sensors journal represents only a small sampling of the technical contributions from the sensors ocean. On behalf of our organizing committee, we are highly thankful to the editor and publisher of Sensors journal for their acceptance to publish these articles and extended thanks to sponsoring agencies and participants for making the grand success of I3S 2004 and referees for the publication of the special issue.

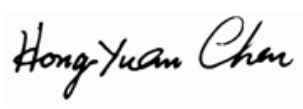

Hongyuan Chen, Conference Chairman, I3S 2004

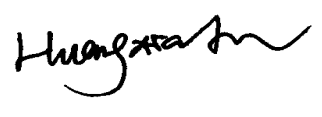

Huangxian Ju, Executive Chairman, I3S 2004, Associate Editor, Sensors

(C) 2005 by MDPI (http://www.mdpi.net). Reproduction is permitted for noncommercial purposes. 